\title{
O TEMPO DA COMUNIDADE E O TEMPO DO TURISMO: NOTAS SOBRE DUAS FESTAS
}

\author{
Emília Araújo \\ Centro de Estudos de Comunicação e Sociedade, Instituto de Ciências Sociais, Universidade do Minho \\ Márcia Silva \\ Centro de Estudos de Comunicação e Sociedade, Instituto de Ciências Sociais, Universidade do Minho \\ Rita Ribeiro \\ Centro de Estudos de Comunicação e Sociedade, Instituto de Ciências Sociais, Universidade do Minho
}

\begin{abstract}
RESUMO
Este artigo explora algumas das principais implicações e desafios que o processo crescente de turistificação das festas de caráter religioso e popular pode representar para as comunidades locais, num momento em que se tornam ofertas turísticas potenciais, com exposição crescente nos mais diversos tipos de média. Em Portugal, celebram-se anualmente muitas festas populares que, sendo de caráter religioso, são expressão do entrecruzamento de elementos diversos, ligados tanto ao tempo sagrado, como ao tempo natural e agrícola e ao tempo profano. Tal como acontece com outros tipos de eventos de caráter popular e religioso, as festas são cada vez mais perspetivadas como potenciais "produtos" turísticos que servem para expor a singularidade das comunidades detentoras e atrair a atenção de visitantes. Neste texto, pretende-se discutir a dificuldade teórica e metodológica de pensar separadamente o tempo da comunidade, do tempo do turismo, atendendo ao caráter identitário que a festa adquire. Este exercício é baseado numa exploração de informação recolhida em trabalhos realizados e em curso acerca de duas festividades que passam, cada uma a seu modo, por estes processos na atualidade: a Bugiada e Mouriscada ou S. João de Sobrado e a Semana Santa em Braga.
\end{abstract}

Palavras-ChaVe

festa; Bugiada e Mouriscada de Sobrado; Semana Santa de Braga; tempo; sustentabilidade; comunidade

\section{TIME OF THE COMMUNITY AND TIME OF TOURISM: NOTES ABOUT TWO FESTIVITIES}

\begin{abstract}
This article explores some of the principal implications and challenges that the rising touristification process of religious and popular festivals may have for local communities, at a time when they are becoming potential tourist attractions, with rising exposure in a broad range of media. In Portugal, many popular festivities are annually celebrated that have a religious character and also reflect the intersection of various elements, linked to both the religious calendar, and to natural and agricultural time and to secular time. As with other types of popular and religious events, such festivities are increasingly seen as potential tourism "products" that can reveal the uniqueness of the host communities and attract visitors. In this text, we intend to discuss the theoretical and methodological difficulty of thinking about the festivity separately from the local population that organises and participates in it, and which feels it a core element of local identity.
\end{abstract}


This exercise is based on analysis of information gathered from previous and ongoing research work into two festivities that are each experiencing such processes today, in their own different ways: the festivity of Bugiada e Mouriscada, or S. João de Sobrado, and the Semana Santa (Holy Week) of Braga.

\section{KEYWORDS}

festivity; Bugiada e Mouriscada of Sobrado; Semana Santa of Braga; time, sustainability; community

\section{INTRODUÇÃO}

Tem de haver paixão para se dançar bem. Tem de haver, acima de tudo, paixão. É a dança mais linda que pode haver. Tens de olhar para a dança com classe porque tu és um mourisqueiro! Um mouro! És um gajo com imponência! Tens uma farda, tens ouro, tens uma espada, tens a cara descoberta, umas botinhas e tens de ser bonito a dançar. Tens de ser vaidoso. E quando se é vaidoso a dança tem de ser vaidosa também. Outra coisa essencial, como dizia um senhor muito antigo para mim: ouvido sempre na caixa! É a caixa que comanda tudo. Só tens uma ordem para dar, duas ordens: ou marcha mais rápido ou marcha mais devagar e só tens a dar a ordem "é para fechar" e, quando é para fechar, muda o ritmo. (residente em Sobrado, participante da festa da Bugiada e Mouriscada)

As problemáticas das mobilidades no turismo, juntamente com o estudo dos impactes socioculturais do turismo, têm tido cada vez mais eco nas pesquisas que analisam a forma como as comunidades locais são atingidas pela atividade turística e que procuram identificar modos de construção de vínculos entre o turista e os locais visitados (Domínguez, 2019).

Outras análises têm-se debruçado sobre as tensões e implicações da turistificação da cultura (e dos objetos e rituais da cultura) apoiada pelos média e, por vezes, alimentada pelas próprias populações, na configuração e significados dos elementos culturais no seio das comunidades (Pinto-Coelho \& Pinto, 2018). Falamos, nomeadamente, da capacidade de o turismo favorecer diversas possibilidades de rutura do tempo histórico dessas populações, instigando-as a adaptarem-se a outros tipos de agendamento condizentes com as necessidades e as temporalidades da oferta turística. Trata-se, para todos os efeitos, de dinâmicas impulsionadoras de várias formas de convivência, adaptação ou resistência, que importa estudar e problematizar.

Deste ponto de vista, o artigo questiona e descreve como e em que circunstâncias o tempo do turismo se cruza com o tempo e as temporalidades da comunidade e da (sua) festa.

O texto conta com a exploração empírica de duas festas específicas: por um lado, a festa de S. João, em Sobrado. Esta festa, conhecida por Bugiada e Mouriscada possui 
reconhecido valor patrimonial e cultural. Ela figura como uma das marcas do concelho de Valongo, distrito do Porto, no Norte de Portugal. Por outro, a Semana Santa em Braga. Esta festa tem, igualmente, ganho reconhecimento internacional.

O estudo empírico envolveu a observação direta e a realização de entrevistas a residentes e a visitantes, em ambas as festas, com pesquisa que decorreu nos períodos das festividades e também fora destas, ao longo do ano de preparação.

\section{CONCEITOS E EXPLORAÇÕES TEÓRICAS}

As sociedades contemporâneas dispõem de instrumentos e dispositivos que colaboram para a intensificação da instantaneidade e para a realização da possibilidade constante de concretizar mudanças no espaço e no tempo (Bauman, 1999). Vários autores têm vindo a analisar criticamente o modo como a existência de tais dispositivos, paralela à valorização da mobilidade e dos estilos e vida, implica gerir desafios constantes provocados pela disrupção no tempo natural e histórico-social ou cultural dos lugares, das comunidades e dos grupos (Berre \& Bretesché, 2018; Bravo, 2010; Némoz, 2018; Jiménez, 2009; Tutiaux-Guillon, 2013).

Apesar de poderem ser desiguais, a mobilidade e a deslocação permanentes marcam o modo de estar moderno que se pauta pela capacidade de nomadismo e descoberta constante. A juntar a esta tendência, está a possibilidade crescente de uso de tecnologias diversas que tornam qualquer objeto, evento ou fenómeno, não só divulgável a qualquer momento e distância, como potencialmente consumível a qualquer altura e de forma imediata. O consumo alimenta o consumo e muita da atividade turística explica-se pela capacidade de tornar tanto artefactos como práticas e memórias, não só imediatamente consumíveis, como oferecê-los em larga escala e de forma massificada. É perfeitamente entendível assumir-se que qualquer elemento sujeito a exploração com caráter turístico é objeto contínuo de mudanças e reconfigurações, por mais impercetíveis que estas sejam, no plano do tempo conjuntural; o que equivale a admitir a relativa fugacidade dos elementos originais ou "autênticos". Todavia, analisados no plano do tempo estrutural, qualquer um dos objetos mencionados se tornam, igualmente, objetos de visita turística potencialmente massificada devido à divulgação e à projeção que se faz dos mesmos. Este processo é particularmente observável no caso do turismo religioso ou cultural que mobiliza elementos integrantes das identidades das populações, não só locais, mas também globais (observe-se o que acontece em áreas naturais "descobertas" para a fruição turística).

Tais “identidades", por razões que podem ser quase diametralmente opostas tentativa de posse, bairrismo, regionalismo, nacionalismo, ou tentativa de abertura, interação, mudança e aspiração sociocultural - atuam vulgarmente na "fixação" do tempo. Podem pretender preservar essas comunidades transformadas, sob o ponto de vista das suas caraterísticas e habitats "naturais", num tempo de caráter circular. Mas também podem pretender oferecê-las transformadas em resultado da própria exposição e participação turística. O certo é que qualquer processo que visa o aumento da visibilidade social de um objeto cultural, e muito concretamente das festividades, eventos e 
performances, abre-se a essa tensão: entre receber o olhar externo, com possível obtenção de recompensas materiais e simbólicas; e gerir os efeitos desse processo que pode implicar responder a outros ritmos. Esta é uma tensão que está presente nos estudos sobre o desenvolvimento sustentável, sendo de destacar a abordagem de Arjun Appadurai (2013) às relações entre cultura e economia, ao defender a necessidade de mais envolvimento das populações na definição dos seus futuros que evitem o seu esgotamento. As festividades e as performances, ao serem objeto de exposição e divulgação, suscitam a mesma tensão, entre permanência e mudança; abertura e resistência. E, no contexto da valorização dos "produtos intangíveis", observa-se que os artefactos do passado sobressaem nas ofertas de turismo cultural e religioso, sendo cada vez mais proeminente o uso do tempo e da temporalidade como objetos de troca: é a manipulação do tempo que se torna objeto comercial. Isso acontece também "com as feiras e as recreações/ performances representativas e celebrativas de certos acontecimentos narrativos, o que conduz ao processo de transformação que envolve a fabricação de uma experiência para torná-lo mais atraente para o turista" (McKercher, Ho \& Cros, 2004, p. 395).

David Harvey $(2016)^{1}$, ao explicitar os contornos capitalistas dos projetos turísticos atuais, fala-nos sobre os processos de reconfiguração e aproveitamento das cidades e dos espaços urbanos. Interpreta o turismo como um dos eixos centrais do capitalismo hipermoderno em que a experiência da instantaneidade é o elemento central de troca. A tese de Harvey demonstra que a cultura e o património oferecidos para consumo turístico são suscetíveis de ser cada vez mais objeto de experiências rápidas e efémeras. Tal acontece porque os sujeitos ficam dispostos, sobretudo, a "ver" e a experimentar, mais do que experienciar de forma contínua ou repetida. Tornam-se "flaneurs" (Santos \& Azevedo, 2019) ativos na própria fruição dos objetos, processos e/ou eventos e performances que se tendem a renovar, em resposta aos gostos e aos pedidos dos públicos. A mesma experiência de "flaneurie espacial" e temporal pode ser incorporada e reproduzida pela própria festividade e traduzida na alteração ou redução das performances/ cenas, deslocação das narrativas e/ou atraso e dilatação do tempo. A literatura aponta diversas implicações sugeridas pela pressão da utilização das festas e das festividades como produtos e ofertas turísticas, no que respeita a aspetos muito concretos como o espaço físico existente, riscos e segurança, número de visitantes e infraestruturas em geral. Mas tem sido menos problematizada esta questão da eventual dissonância de tempos a que se resume, em boa parte, a questão da (in)sustentabilidade: entre o tempo das festividades e das performances que se confunde e funde com o tempo da comunidade onde a festa se celebra (tempo endurance) e o tempo da atividade turística e da exploração mediática e económica da mesma (tempo abstrato, em aceleração) que, por norma, representa ou aceleração ou atraso da festa e da comunidade.

No entendimento de Bernadette Quin (2009), enquanto o estudo socioantropológico das festividades tem colhido muita atenção ao longo dos tempos, permitindo descobrir e analisar um conjunto cada vez mais extenso de celebrações, o interesse em analisar as relações entre as festividades e os impactes turísticos tem sido menor. Ou

\footnotetext{
' Palestra proferida por David Harvey (2016), intitulada "Culture and cities: the challenge of tourism". Retirado de http://www.cccb.org/en/multimedia/videos/culture-and-cities-the-challenge-of-tourism/225261\#
} 
seja, tem sido menos tratada a questão dos conflitos de tempo potencialmente originados pela "transformação" da festa (a qual pode corresponder a uma arrumação, arranjo ou limpeza) impelida na base de argumentos apresentados por atores que pretendem "valorizá-la" através da sua maior exposição e capacidade de atração de outros públicos.

Baseada em autores como Formica e Murrmann (1998) e Derret (2003), Quin (2009, p. 16) argumenta que o residente tem um papel central na forma como os festivais e eventos são associados ao bem-estar da comunidade e à coesão social e identidade da mesma. Esta ideia confere substância à tese que vínhamos expondo sobre o interesse em considerar-se na análise da sustentabilidade dos processos de turistificação da festa o entrosamento do tempo da festa com o tempo da comunidade, nas várias modalidades - passado, presente e futuro.

E que significa isto concretamente? Daniel Catala-Perez (2013, p. 165) observa que os festivais são "factos culturais" que fazem recordar "coisas ou eventos profanos através de cerimónias, rituais, celebrações e comemorações". No entendimento do autor, estes eventos são "transmitidos pela tradição". Tal significa que a "identidade" da comunidade e dos indivíduos é construída intrinsecamente por relação com estes eventos que "são" a própria comunidade de pertença, como se lhe pré-existissem. Trata-se de ângulos, um desafio complexo, tanto para quem está dentro da comunidade como fora, e qualquer que seja o seu papel ou função.

Uma das críticas mais vigorosas ao modo de entender o aproveitamento dos territórios, lugares, festividades e/ou rituais prende-se com o risco de "descaracterização", a sua alienação e a perda de laços que ligam cada um desses objetos e/ou fenómenos à comunidade com a qual se fundem na constituição de uma identidade única e própria vulgarmente traduzida pela população como o "ser da festa". Tal como Muchazondida Mkono (2012) argumenta, a questão da autenticidade, particularmente nos casos dos eventos e festividades, continua a suscitar várias interrogações. Por um lado, porque permite abrir uma porta fácil à promoção da festa e do seu caráter "popular", principalmente por parte de alguma elite que possa estar envolvida no aproveitamento material e simbólico da festa. Por outro, porque a "autenticidade" é uma das qualidades mais discutíveis de qualquer produto/evento (Rickly-Boyd, 2012).

Na perspetiva de Eva Parga e Pablo Alonso González (2019), as práticas de turismo sustentável implicam considerar o valor social e simbólico dos lugares, o que se traduz na tomada em consideração de dimensões estéticas, económicas, assim como dos riscos. A cultura é suscetível de jogos de poder e luta política. Com efeito, as discussões em redor da turistificação das festas e das performances populares são recentes e remetem invariavelmente para as tensões latentes na exposição das festividades, face ao potencial distanciamento ou desenraizamento da festividade em relação à comunidade. Ademais deste distanciamento, podem estar ligadas a estratégias diversas de exposição do "povo" e das suas performances dirigidas por elites que tornam este "povo", simultaneamente, objeto de consumo e consumidor (Catenacci, 2001).

As festividades de caráter religioso têm um papel fundamental na organização da vida das comunidades ao longo da história. O seu papel é vital na dinamização dos usos do tempo dos vários grupos nas comunidades. Tal como Durkheim (1979/1912) explicita, 
o tempo das festas integra o tempo social. Por isso, as festas instituem tempos de rutura e de efervescência. Porque integram os ritmos sociais das comunidades, estão articuladas com vários outros tempos, entre os quais, os ritmos agrícolas. Por seu turno, estes associam-se aos ritmos naturais e religiosos que "marcam" o tempo, ao institucionalizarem os momentos de agradecimento da comunidade a entidades sobrenaturais em quem se confia a proteção em todas as esferas da vida. Por isso, as festividades tiveram papel determinante no desenvolvimento das atividades económicas (Amirou, 2007; Secall, 2009). Neste quadro, devemos analisar o turismo religioso como algo que está profundamente ligado ao calendário religioso de determinado lugar (Tendeiro, 2010) podendo ser definido como "aquele tipo de turismo que tem como motivação a visita a lugares sagrados (santuários, conventos, mosteiros, igrejas, catedrais...) e a participação em celebrações religiosas (Semana Santa de Sevilha, por exemplo...)" (Parellada, 2009, p. 22).

É certo que hoje o turismo religioso não define apenas viagens motivadas por elementos religiosos. O conhecimento dos lugares, a busca do isolamento, a reflexividade individual são também motivos de mobilidade turística. Por isso, persiste uma diferença entre o turista religioso e o peregrino que se centra na "dimensão divina de um sítio sagrado" (Wiśniewski, 2019, pp. 206-207). Independentemente da definição que possa ser utilizada, importa realçar que as deslocações em razão de motivações turísticas associadas a acontecimentos e festividades religiosas festivais tem ganho grande projeção no mercado. Esta expansão traz inevitavelmente vários questionamentos.

Assim, na segunda parte do artigo e mantendo a tese sobre a tendência para o aproveitamento da festa como produto de oferta turística, com potencial de oferta a públicos mais estranhos à festa, iremos explorar algumas ideias sobre a festa de S. João de Sobrado (Bugiada e Mouriscada) e a Semana Santa em Braga.

\section{S. João de Sobrado (Bugiada e Mouriscada)}

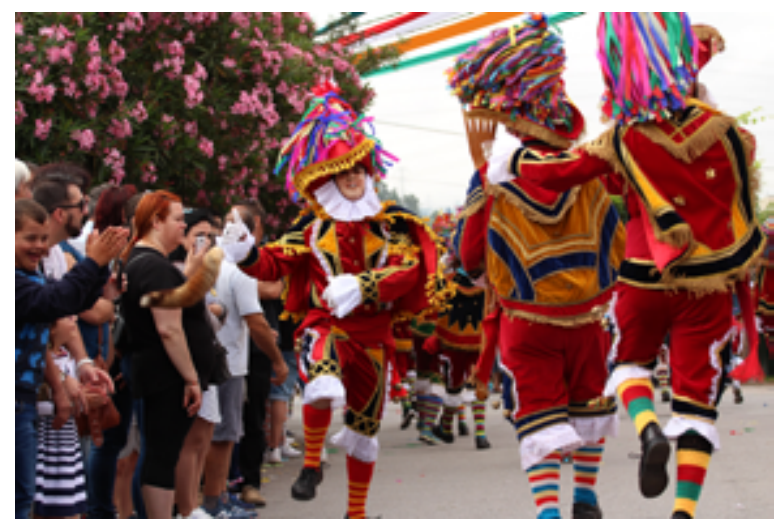

Figura 1: Detalhe da dança dos Bugios (S. João de Sobrado - Bugiada e Mouriscada) Créditos: Luís António Santos

A festa da Bugiada e Mouriscada acontece no dia da celebração de S. João, a 24 de junho na vila de Sobrado, concelho de Valongo (Pinto et al., 2016). A festa decorre 
desde manhã cedo até ao anoitecer, incluindo também um arraial nas noites anteriores. Mantém-se substancialmente igual na estrutura, tal como documentada em trabalhos anteriores (Gallop, 1961/1936), embora inclua diversas transformações em termos de conteúdos, incluindo cenas e performances. A festa centra-se na representação ou recriação de uma lenda que narra a disputa entre mouros e cristãos pela posse da imagem de S. João. Durante o dia, as cenas profanas, caracterizadas por performances que envolvem os bugios e os mourisqueiros, sobretudo danças e encenação sem texto, tomam lugar em vários locais de Sobrado, tendo como protagonistas principais os residentes. As cerimónias religiosas acontecem também quase em simultâneo e decorrem principalmente na igreja, incluindo missa solene e procissão na qual são os mourisqueiros que carregam os andores dos santos (Pinto et al., 2016).

Um dos traços principais desta festa, é a ligação com a comunidade e a capacidade de a reproduzir no tempo. Quando se pergunta a um participante da comunidade por que razão gosta desta festa, a resposta é recorrente "é a paixão que a gente tem. É aquilo que está no sangue, não há hipótese (...) É, não há hipótese". As entrevistas realizadas a pessoas da comunidade mostram que não há quem não participe na festa de algum modo e em algum momento da sua vida: "se desaparecesse o S. João acho que esta freguesia ficava desorientada. A sério! É um ponto de referência nosso, para o bem e para o mal". O sentimento de pertença e de "posse" da festa constitui e configura-se a identidade coletiva da comunidade. "porque é uma tradição. Tem muitos anos. Eu não sei explicar. A gente gosta tanto disto que nem sabe explicar. Trabalha-se um ano inteiro para isto, para um dia que passa tão depressa" (residente em Sobrado, participante da festa da Bugiada e Mouriscada).

No excerto seguinte é evidenciado este sentimento complexo de identificação com a festa, não apenas pelo que é no momento presente, mas, principalmente, pelo que ela representa ao longo do tempo de vida dos sujeitos e, portanto, pelo que lhes trouxe na construção do quotidiano:

a paixão é aquilo que é mais difícil de explicar. Para mim a paixão é aquilo que nós sentimos e vivemos no nosso extremo de fantasia em que nós (...) a paixão, a paixão é aquela situação em que tu sabes que chegas àquele dia e sabes que vais participar naquilo que tu gostas e que te diz muito. (residente em Sobrado, participante da festa da Bugiada e Mouriscada)

A expressão da "paixão" pela festa cultiva-se deste tenra idade, quando começa o envolvimento com as várias atividades e imaginários sobre o modo como se ela se prepara. Esta familiarização antecipada com todo o universo da festa surge muito evidente nos discursos das pessoas. Elas referem-se à festa como algo que "está no sangue", incontestável, "inata”, visceralmente constitutiva do corpo e da alma. Há, portanto, uma fusão intrínseca dos sujeitos com a comunidade na festa e através da festa.

É o gosto pela festa. Desde os meus sete, oito anos lembro-me disto. A gente tem este gosto de ir. Está no sangue. Quando eu era novo, nos meus vinte, 
vinte e tal, e chegava a casa às cinco horas da manhã, deitava-me na cama, já com uns copos e depois "oh, não vou!" mas quando ouvíamos passar os primeiros bugios "tlim tlim tlim" eu até ia bêbado e tudo! Eles passavam aí com os guizos "tlim, tlim, tlim!" e eu enfiava a farda e toca a andar! (residente em Sobrado, participante da festa da Bugiada e Mouriscada)

Para mim, a Prisão do Velho é fantástica, mas para mim quem me tira a Dança de Entrada tira-me tudo. É o auge da festa para mim porque é ali que é tudo teu. É ali que mostras à terra quem és e porquê durante tantos anos batalhaste e te sacrificaste. A avenida é toda tua. Tens os olhos todos postos em ti e aí a responsabilidade também é muito grande. Se tenho saudades disso? Tenho muito. (residente em Sobrado, participante da festa da Bugiada e Mouriscada)

Na figura abaixo apresentamos um pequeno exercício de análise ao conteúdo das respostas fornecidas no decorrer de um questionário aplicado no dia da festa, em 2016, a 63 pessoas. Observa-se que a festa de S. João de Sobrado é entendida como um dos elementos principais da identidade do sobradense. É uma caraterística "genética" porque a festa é "tradição" e é "paixão" que está no "sangue" e no "coração", "arrepia" e é "diferente".

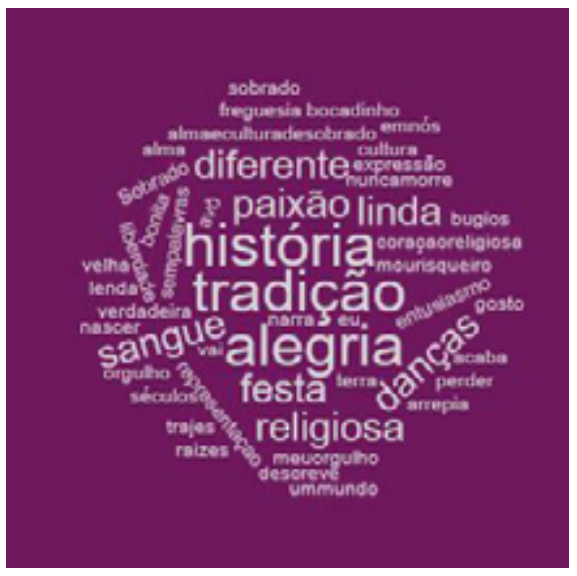

Figura 2: Classificações da festa de S. João de Sobrado Bugiada e Mouriscada feita pelos residentes e participantes Fonte: Inquérito por questionário realizado aos visitantes da festa $(2016, \mathrm{~N}=63)$

Assim, a "abertura" e a "expansão" ao turismo suscitam diversas tensões. Estas não implicam apenas a ideia de "perda" da festa. Há também o receio de mudança e alienação da mesma. É notória a apreensão de que a festa possa ser transladada no tempo ou no espaço, de forma a corresponder a programações turísticas. Por isso, os residentes tornam-se vigilantes relativamente à forma como a festa pode vir a ser objeto de consumo turístico mais massificado. Muitas vezes, esta abertura ao turismo pode coincidir também com uma deslocação temporal. Ou seja, a festa é objeto de reprodução e de simulação, de forma a ser vista, vivida e interpretada ou experienciada de forma 
pública - aos Outros. Para a comunidade, este é um desafio difícil de aceitar devido ao receio que a mostra ou divulgação reduzam a amplitude dramática e efervescente (a cor, o pó) da festa a uma caricatura de si própria.

Já foi levado ao Porto. Foi uma má interpretação da parte de quem, de quem quis levar, não de quem foi lá caracterizar, penso eu. Mas acho que não devia ter saído. Sai daqui as máscaras, sai daqui o chapéu, sai daqui a roupa para dar uma cor, e o que é realmente a festa e a curiosidade que deve ser colocada nas pessoas para verem o que é a festa, o cheiro, o sabor, o pó é no dia 24 e é em Sobrado. Acho que a festa deve ser o mais divulgada possível, independentemente de cabermos todos, ou não. Se não coubermos todos alguns saem para outros ficarem. É como em outras festas. (residente em Sobrado, participante da festa da Bugiada e Mouriscada).

Não é, todavia, uma vigilância partilhada por todos de igual modo. Por um lado, há interesse em alargar a divulgação da festa no país e no estrangeiro. Por isso, fala-se da necessidade de expandir a divulgação da festa através dos canais nacionais de televisão. Por outro, apresentam-se vários limites a esta exposição, designadamente associados às infraestruturas, recursos e limites quanto à "posse" da festa e à sua eventual "descaraterização". O excerto abaixo é revelador destas tensões. O entrevistado começa por afirmar enfaticamente a necessidade de a festa se manter a mesma: "é assim [a festa tal como é agora]: ou agrada ou não agrada". Ainda que explique por que pensa ser importante divulgá-la, não a apresenta como objeto de oferta turística passível de ser transformada:

é assim [a festa tal como é agora]: ou agrada ou não agrada. Eles [políticos] já a divulgaram. Já quiseram pôr isto a património não sei do quê, bem havia umas coisas (...) chega ao dia de S. João e a gente não vê nem mais nem menos que as mesmas pessoas. Pode vir um jornalista, uma pessoa que vem fotografar, pode vir uma televisão, o Porto Canal e assim, mas não se vê assim ninguém de Espanha, nem de França, nem do Algarve, nem de Lisboa (...) É assim: gostar, nós também não temos muitos meios para acolher aqui essas pessoas. É como [a festa x], a nossa festa é muito melhor que [essa] e essa está sempre na televisão. Às vezes entrevistam pessoas que foram de longe para ver a festa. Nós aqui o longe é aqui da zona, pode vir um, sei lá, por exemplo, o irmão do Sr. X que já trouxe tanta gente porque de resto é tudo daqui desta zona, Campo, Valongo (...). As pessoas ouvem falar, mas nunca vêm cá ver. (Residente em Sobrado, participante da festa da Bugiada e Mouriscada)

Agora, se realmente isto partir para uma coisa para além do distrito do Porto nós em vez de dançar 40 minutos vamos ter de dançar duas horas e meia para que as pessoas todas possam ver. É essa a diferença e é isso que me assusta um bocado. Não vamos conseguir assimilar tanta gente 
a assistir. É este o meu principal receio. De resto, acho que toda a gente deveria assistir e saber em concreto o que é a história de S. João de Sobrado. Agora isso é que me assusta um bocado. Imagine 10 mil pessoas aqui! Agora imagine 100 mil! Quando assistir ao S. João vai ver o espetáculo que é e o aglomerado de gente a assistir. Se nós tivermos isto a nível mundial, onde é que vamos meter tanta gente? O que é que vai acontecer à freguesia de Sobrado? Percebe? Isso é que me assusta. Agora, a festa vai ser sempre a mesma. Sempre com os mesmos aficionados e sempre com os meus mesmos bugios a tentar manter a tradição. (residente em Sobrado, participante da festa da Bugiada e Mouriscada)

Com efeito, as festividades acontecem. Têm um momento concreto para se revelarem. Implicam performance e esta ocorre num tempo singular: o dia da festa. A permeabilidade à mudança é baixa e vivida com ansiedade. Nesta festa, observam-se variações no número de participantes em cada performance, cuja duração também varia. $A$ indumentária também foi sendo modificada ao longo dos anos. Mas todas estas variações passam pelo crivo crítico, tal como se observa a partir do excerto apresentado a seguir.

Eu fui criado aqui, a Bugiada diz-me muito (...) tu tens que participar e tens de ser crítico, em duplo sentido: nós somos críticos antes da festa, durante a festa e depois da festa. Porque nós sermos críticos também faz parte do envolvimento e do testemunho. Nós, ao sermos críticos, somos porque gostamos, se nós às vezes criticamos alguma coisa é uma crítica construtiva. Se você me fizer uma pergunta agora: "se tu fosses outra vez [dessa personagem] fazias exatamente aquilo que fizeste?" e eu vou-lhe dizer: "vou tentar fazer exatamente o que fiz e mais alguma coisa!". E mais alguma coisa! Há uma coisa que eu devia ter feito, fiz, mas fiz mal, devia ter feito melhor. (residente em Sobrado, participante da festa da Bugiada e Mouriscada)

O próximo excerto demonstra esta necessidade intrínseca de preservar a festa que é "nossa", ainda que, tal como dissemos antes, possa ser "divulgada" e dada a conhecer a quem não é exigida competência para conhecer os meandros da festa, mas a suas manifestações.

É bonito dar a conhecer ao país, que nós temos aqui uma festa bonita, bonita aos nossos olhos porque a festa é nossa, mas o que eu tenho conhecimento de amigos que vieram aqui é que gostaram muito e ficaram encantados com a beleza da festa e muitos deles nem têm conhecimento do que se está a desenrolar, mas as danças, os gestos, muita gente fica de boca aberta. Acho que os meios de comunicação deviam divulgar mais, mas também para isso quem está cá tem que a trabalhar não são os de fora que têm que a trabalhar, os da terra têm que mostrar o que querem. Se querem que ela seja divulgada, ou não (...). Mas é bom que a divulguem e 
que venha muita gente para aqui. Se é positivo para os outros porque não há de ser para nós? (residente em Sobrado, participante da festa da Bugiada e Mouriscada)

No caso particular desta festa, ficam mais evidentes as considerações sobre diversos tempos que entram ou podem entrar em conflito, quando a festa se torna objeto potencial de oferta turística. Estes devem ser considerados no tocante à problematização da sustentabilidade desse processo: i) o tempo estrutural e histórico da comunidade, no qual a festa se assume como espécie de mito fundacional, neste caso, da freguesia, cuja identidade se renova e celebra a cada momento em que a festa se renova anualmente; ii) o tempo da festa que se organiza em direta correspondência com esse tempo estrutural e identidade (ao qual se ligam diversos outros tempos e ritmos anuais e durante o próprio dia da festa); iii) e o tempo real e cronológico em que a festa ocorre e se organiza (o tempo que inclui o que a comunidade é e como se pensa num determinado ano).

\section{A Semana Santa de Braga}

O turismo religioso, o turismo negro e o turismo cultural estão fortemente ligados a heranças religiosas fixadas em objetos de património material e, sobretudo, nas festividades, celebrações e eventos de caráter religioso e sagrado.

As viagens a destinos de caráter religioso constituem um importante subsetor do mercado turístico da Europa e prendem-se com o progresso da globalização (Ritzer \& Liska, 1997). Anualmente mais de 300 milhões de pessoas visitam os mais importantes lugares religiosos do mundo (UNWTO, 2016). O turismo religioso é particularmente difícil de definir, uma vez que se trata de um fenómeno onde se cruzam motivações e práticas de natureza diversa. A visita a locais religiosos não configura apenas uma peregrinação pessoal associada à devoção religiosa, mas pode decorrer, em alternativa ou concomitantemente, de motivações culturais e de entretenimento. A viagem de peregrinação religiosa, quase sempre, faz do peregrino um turista religioso, na medida em que este adapta a sua viagem às características do processo turístico, isto é, assume um comportamento de consumo turístico (Santos, 2006).

A participação em eventos religiosos vem-se transformando em expressão - para os residentes - e experienciação - para os visitantes - da tradição local, ligada à identidade cultural dos lugares e das suas gentes. Daqui resulta que a peregrinação religiosa é não um fim, mas parte de uma prática múltipla e híbrida que permite, cumulativamente, a experiência de natureza religiosa (vivida individual e coletivamente), a visita a locais do património cultural local (igrejas, mosteiros, museus, etc.), a visita a localidades próximas, a fruição da cultura local (gastronomia, artesanato, etc.). É possível afirmar, portanto que, na atualidade, nem todos os turistas que se deslocam a lugares religiosos são motivados pela religião, mas também por interesse cultural, histórico, arquitetural ou outro (Neves, 2010; Fernandes, Pimenta, Gonçalves \& Rachão, 2012).

Como tal, é difícil traçar um limite entre viagem laica e peregrinação, devido ao facto de a motivação religiosa não excluir motivos profanos. Do ponto de vista dos Estudos 
do Turismo, perde pertinência a distinção entre práticas turísticas profanas e práticas orientadas para o sagrado; o que encontramos é uma combinação entre religião, cultura e turismo. Como refere (Amirou, 2007, p. 138), "as práticas religiosas modernas fazem parte da rubrica dos lazeres".

Braga é conhecida pelas suas festividades de cunho religioso, nomeadamente católicas. Conhecida como cidade dos Arcebispos, é uma cidade com inúmeras referências religiosas, desde igrejas, capelas, mosteiros, seminários, museus e estatuária com referência à religião católica. A Semana Santa em Braga constitui uma celebração de grande destaque que envolve milhares de participantes, visitantes e população residente. De ano para ano este evento tem-se tornado um ícone da cidade, quer pela grandiosidade e complexidade de celebrações religiosas, quer pelos eventos culturais que constituem o programa da Semana Santa.

A organização da Semana Santa está a cargo de uma comissão composta por membros da Igreja, dos quais o Cabido da Sé de Braga, a Irmandade da Misericórdia, a Irmandade de Santa Cruz, e instituições de carácter laico, a Câmara Municipal de Braga, o Turismo do Porto e Norte de Portugal e a Associação Comercial de Braga. Mas nem sempre foi assim. Ao longo dos anos, resultado do forte impacto da Semana Santa na cidade estas entidades foram-se aliando à iniciativa.

Em 1948, o cartaz da semana já convidava a visitar a cidade. Devemos salientar o slogan que referia as "imponentes cerimónias religiosas" e demonstra a importância e valorização da componente religiosa.

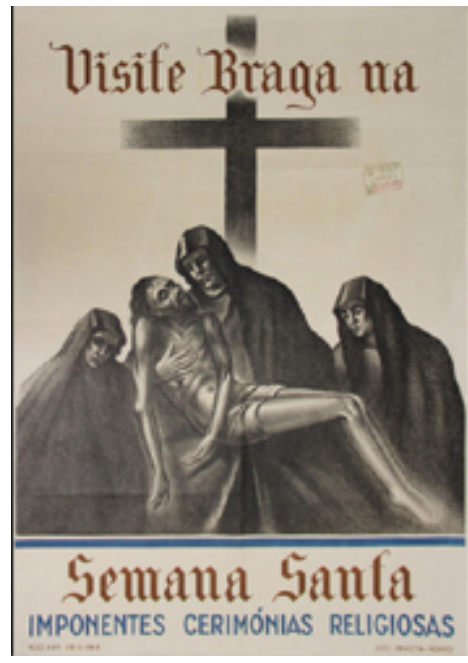

Figura 3: Cartaz da Semana Santa (1948)

Fonte: https://semanasantabraga.com/arquivo/cartazes/

A 17 de abril de 1965, era título no jornal Diário do Minho: "aos milhares de pessoas já presentes em Braga, muitos outros milhares vieram juntar-se-lhes durante o dia de ontem para viver em cheio a Sexta-Feira Santa". Já neste período eram muitas as pessoas que se deslocavam à cidade para participar nas festividades religiosas. A partir de 
1986 começa a fazer-se referência ao turismo nos cartazes da Semana Santa. Ao longo dos anos vem-se verificando um aumento dos apoios ao evento, nomeadamente da Câmara Municipal de Braga e da Associação Comercial de Braga.

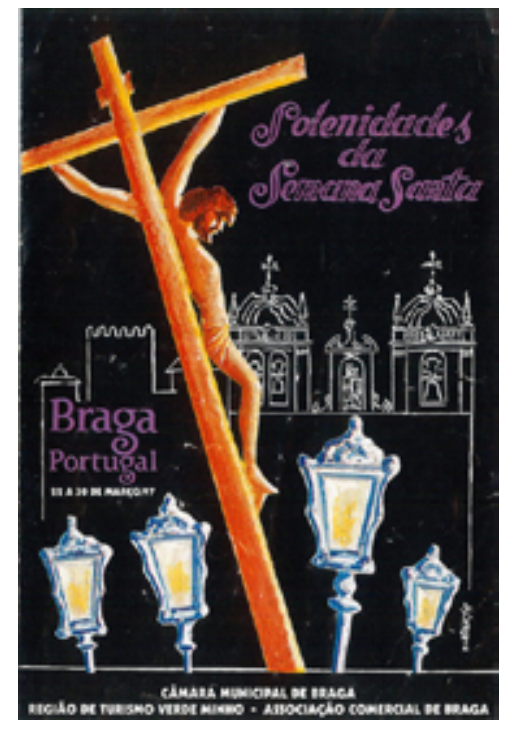

Figura 4: Cartaz da Semana Santa (1997) Fonte: https://semanasantabraga.com/arquivo/cartazes/

Em 2002, surge o interesse de potenciar o turismo religioso, dado o elevado número de turistas e visitantes que chegava à cidade por ocasião das celebrações religiosas. Desta forma, a Associação Comercial de Braga apresentou o projeto "Turismo Religioso - promoção e dinamização do turismo religioso como motor de desenvolvimento regional" (2003), que tinha como principal objetivo a captação de visitantes para a cidade. Em 2013, a necessidade de "prender turistas" constituiu um objetivo principal da comissão organizadora da festa. Nesse sentido, foram inauguradas diversas exposições e organizado o cortejo dos guiões com o propósito de dar a conhecer aos bracarenses e aos turistas o património subjacente às procissões de Passos da cidade. Os "guiões" são bandeiras típicas, com alto valor afetivo e simbólico, utilizadas nas procissões de Passos nas freguesias.

A partir de 2003, e segundo dados do Posto de Turismo de Braga, assiste-se ao crescimento do número de visitantes na cidade de Braga, o que é acompanhado de alterações significativas na programação da Semana Santa, que passa a incluir concertos, exposições e conferências, procissões com cenas performativas de carácter teatral, para além das procissões e celebrações na Sé Catedral. Segundo um estudo do Turismo Porto e Norte de Portugal realizado em 2011, a principal motivação do turista para visitar a cidade de Braga na Semana Santa é o lazer. O estudo revela que os turistas apreciam, em primeiro lugar, a beleza das praças/ruas e, em segundo lugar, a diversidade de procissões/eventos, o que demonstra a dimensão mais cultural, do que propriamente religiosa das práticas turísticas de quem visita a cidade de Braga durante as celebrações da Semana Santa. 
À medida que a cidade é reconhecida nacional e internacionalmente pela sua atração religiosa e cultural, tem sido galopante o interesse por parte de entidades laicas, intrínseca ou historicamente ligadas à festa, em expandir a divulgação da festa e "transformá-la", no sentido de constituir oferta turística a visitantes de outras partes do país e do estrangeiro. O programa da Semana Santa envolve cada vez mais stakeholders, sendo que os comerciantes são incentivados à criação de montras alusivas às festividades. Os residentes também podem participar de diversas iniciativas integradas na mesma programação, como concursos que visam o registo fotográfico, que pretende a divulgação e envolvimento da população.

Neste caso, as tensões mais salientes que se evidenciam não se verificam por via da identificação tão intrinsecamente identitária entre a festa e a população, como o disséramos em relação à festa de S. João de Sobrado, mas por via da tensão entre turismo religioso e turismo massificado, de consumo efémero e mais valorizado enquanto património cultural do que pela devoção e experiência religiosa. Segundo o Arcebispo Primaz de Braga, em comunicado ao Diário do Minho (29 de março 2015, p. 7), a Semana Santa "não pode ser uma organização de eventos culturais" que estimulam a atividade turística. Para o clérigo, "a cidade de Braga devia ser capaz de manter o que é verdadeiramente importante na Semana Santa. E o importante é a contemplação da cruz de Cristo". Acrescenta também que "a Semana Santa não deve ficar apenas por um cartaz turístico muito bem organizado, é preciso que diga o que deve dizer e fale ao coração das pessoas".

Mas é certo que gradualmente, as entidades laicais fomentam de forma intensiva a atração turística, através dos meios de comunicação social, promovendo parcerias com empresas locais. Em entrevista, a Vereadora da Cultura e da Educação da Câmara Municipal de Braga² afirma que

temos de receber bem para que o passa-palavra seja positivo. O facto de conseguirmos que as televisões venham cá fazer reportagens faz toda a diferença. O poder da televisão é muito grande, mas nós ainda estamos a sofrer muito por estarmos muito longe. É uma manifestação religiosa que, mesmo para quem não é crente, fica maravilhado.

No decurso da entrevista a Vereadora Lídia Dias afirma que "a comissão da Semana Santa também tem que dar um salto, porque é muito fechada e é muito difícil; para os desafios cada vez maiores de promoção do turismo tem de se olhar de outra forma".

${ }^{2}$ Entrevista realizada por Márcia Silva, Braga (2015). 


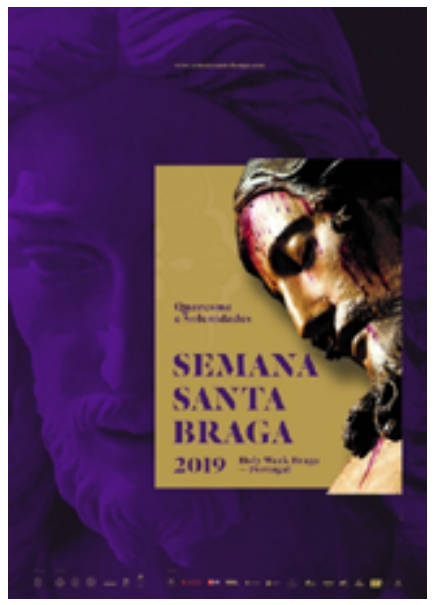

Figura 5: Cartaz da Semana Santa

Fonte: https://semanasantabraga.com/arquivo/cartazes/

Em 2012, foram produzidos diversos produtos alusivos à Semana Santa como forma de promoção da imagem das celebrações e de recordação da cidade. A principal figura é o "Farricoco". No entanto, existem outros produtos, como postais, fotografias, material escolar. Em paralelo às festividades religiosas, foi criado o "Mercado da Páscoa em Braga" que assegura animação ao centro histórico e dá a conhecer os produtos da região, tais como artesanato e doçaria. De acordo com a informação recolhida em inquérito por questionário ( $n=45$ ), num estudo já publicado (Silva \& Ribeiro, 2018) a população residente reconhece o interesse na expansão dos eventos da Semana Santa. Os residentes apontam os benefícios económicos como um dos aspetos mais positivos das festividades. Destacam também os contributos para um maior sentido de orgulho pela sua cidade. Consideram que Braga está preparada para acolher os turistas, devido à oferta hoteleira diversificada, às boas condições a oferecer aos turistas e à existência de diversos sítios de interesse turístico. O aumento da poluição e o caos do estacionamento são alguns aspetos que causam insatisfação. Existem, todavia, resistências consideráveis de parte dos residentes à transformação da festa e à necessidade de gerir os efeitos provocados pelo aumento dos visitantes, incluindo a transformação da sequência das performances que integram a festa.

\section{NOTAS CONCLUSIVAS}

As festividades analisadas neste artigo são ambas de carácter religioso, mas bastante distintas quanto à forma como se desenvolvem ao longo do tempo e à ligação que a comunidade estabelece com elas. Também diferem no que respeita à incorporação de elementos profanos e à importância destes na definição identitária da festa.

A primeira, a Bugiada e Mouriscada de Sobrado, compõe-se em grande parte destes elementos que constroem as diversas cenas e performances coreográficas e teatrais e que são, em parte dos momentos festivos, rituais de inversão e críticas ao dia a dia da comunidade e, principalmente, aos poderes que a representam. A turistificação das 
festividades coloca diversos questionamentos do ponto de vista teórico e prático-político. Não só porque as festividades são manifestações cíclicas enraizadas na identidade das comunidades e que se tornam objeto de observação e de exposição a públicos diferenciados e por norma não identificados cultural e socialmente; mas também porque são realidades fluidas, transitórias e dinâmicas atravessadas por diversos processos de transformação e de reconfiguração.

Os casos empíricos sobre os quais nos debruçamos, e muito em particular no caso da festa de Sobrado, mostram a preocupação constante com as possibilidades de "perda da festa" que decorrem da sua divulgação e de eventuais tentativas de domesticação das suas facetas mais subversivas. Remetendo para conceitos como o de autenticidade, cultura popular e horizonte temporal, importa estabelecer formas de conviver e dialogar entre os passados das comunidades e os seus futuros. Tal significa que a festa não poderá ser perspetivada por parte da comunidade como um tempo fechado e datado, a partir do qual se podem estabelecer relações fixas ao longo do tempo com os visitantes. Também não pode ser entendida, por parte dos stakeholders, como um repositório do tempo passado, revistado por vezes de forma nostálgica, mas como algo a preservar enquanto elemento de cultura popular.

Em ambas as festas em análise, os discursos dos residentes e participantes são ambivalentes. Em primeiro lugar relativamente aos benefícios da promoção mediática da festa, que consideram importante e necessária, de modo a dá-la a conhecer ao país e ao mundo. Em segundo lugar, por terem de arcar com os desafios que essa exposição impõe do ponto de lista espacial e logístico e nos tempos da e para a festa. Fica evidente também que, de forma mais ou menos consciente, os residentes e participantes em ambas as festividades, principalmente na festa Bugiada e Mouriscada, vivem os dilemas do enfrentamento da abertura da festa ao exterior da comunidade com bastante intensidade e vislumbre, ao pretenderem que a festa seja conhecida como "tradição centenária" e vivida "pelo país" e ao estarem dispostos a preservá-la de forma a que se mantenha "autêntica".

Assim, a discussão que possamos fazer sobre as implicações e os desafios que se impõem aos bens intangíveis implica mobilizar vários conceitos e atender à necessidade de promover junto das populações conhecimento acerca dos processos que possam ser desencadeados, tendo em vista a divulgação e/ou a conceção de produtos e ofertas turísticas. Esta dimensão participativa é fundamental por duas razões. Por um lado, há uma forte ligação emocional e identitária das populações àquilo que consideram definidor da sua "essência" e que esperam serem conhecidas e visitadas por essa "riqueza". Mas, por outro, impõem-se novas formas de convivência com outras formas de ver, experienciar e consumir a festa, incluindo as enunciadas por especialistas, políticos e académicos.

\section{FinANCIAMENTO}

Este texto decorre, em parte, da investigação realizada no âmbito do projeto "FESTIVITY - Festa, património cultural e sustentabilidade comunitária. Investigação e comunicação no caso da Bugiada e Mouriscada de Sobrado", Ref. PTDC/COM-CSS/31975/2017. 


\section{REFERÊNCIAS}

Amirou, R. (2007). Imaginário turístico e sociabilidades de viagem. Porto: Estratégias Criativas.

Aos milhares de pessoas já presentes em Braga, muitos outros milhares vieram juntar-se-lhes durante o dia de ontem para viver em cheio a Sexta-Feira Santa (1965, 17 de abril). Diário do Minho.

Appadurai, A. (2013). The future as cultural fact: essays on the global condition. London: Verso.

Associação Comercial de Braga (2003). Turismo religioso - promoção e dinamização do turismo religioso como motor de desenvolvimento regional. Braga: Associação Comercial de Braga.

Bauman, Z. (1999). Globalização. As consequências humanas. Rio de Janeiro: Jorge Zahar Editor.

Bravo, C. (2010). Hacia una narrativa de la naturaleza: la psicología ante el reto sustentable. Polis: Revista Latinoamericana, 26. Retirado de http://journals.openedition.org/polis/736

Catala-Perez, D. (2013). Cultural tourism and festivals: seeking a sustainable relationship. In M. M. Molina, V. S. Campos \& M. V. S. Oña (Eds.), Tourism Q Creative Industry. Workshop Proceedings (pp. 165-166). Valência: Universitat Politècnica de València.

Catenacci, V. (2001). Cultura popular entre a tradição e a transformação. São Paulo em Perspetiva, 15(2), 29-35. http://doi.org/10.1590/S0102-88392001000200005

Domínguez, A. Q. (2019). Turismofobia, ou o Turismo como fetiche. Revista do Centro de Pesquisa e Formação SESC, 12018 [Vol. Especial], 22-30. Retirado de https://www.sescsp.org.br/online/ artigo/12160_ALAN+QUAGLIERI+DOMINGUEZ

Durkheim, E. (1979/1912). Les formes élémentaires de la vie religieuse: le système totémique en Australie. Paris: Presses Universitaires de France.

Fernandes, C., Pimenta, E., Gonçalves, F. \& Rachão, S. (2012). A new research approach for religious tourism: the case study of the Portuguese route to Santiago. International Journal of Tourism Policy, 4(2), 83-94. http://doi.org/10.1504/IJTP.2012.048996

Formica, S. \& Murrmann, S. (1998). The effects of group membership and motivation on attendance: an international festival case. Tourism Analysis, 3(3/4), 197-207.

Gallop, R. (1961/1936). Portugal a book offolk ways. Cambridge: University Press.

Jiménez, M. (2009). Sustentabilidad a dos tiempos. Polis - Revista Latinoamericana, 24(8), 357-382. Retirado de https://journals.openedition.org/polis/1673

Le Berre, S. \& Bretesché, S. (2018). Les enjeux sémantiques et temporels du risque à l'heure du développement durable. Temporalités, 28. http://doi.org/10.4000/temporalites.5233

Mckercher, B., Ho, P. \& Cros, H. (2004). Attributes of popular cultural attractions in Hong Kong. Annals of Tourism Research, 31(2), 393-407. https://doi.org/10.1016/j.annals.2003.12.008

Mkono, M. (2013). Contested authenticity in Zimbabwean tourist entertainment. Tese de Doutoramento, Southern Cross University, Lismore. Retirado de https://epubs.scu.edu.au/cgi/viewcontent.cgi?article=1 $313 \&$ context=theses

Némoz, S. (2018). Contretemps et devenirs: les temporalités plurielles de l'habiter à l'heure du développement durable. Temporalités - Revue de Sciences Sociales Et Humaines, 28. http://doi. org/10.4000/temporalites.5618. 
Neves, J. M. de O. (2010). Turismo religioso: espiritualidade, cultura e prática turística? In M. G. M. P. Santos (Ed.), Turismo cultural, territórios e identidades (pp.187-195). Porto: Edições Afrontamento.

Parellada, J. (2009, novembro). El turismo religioso. Sus perfiles. Comunicação apresentada nas Jornadas de delegados de Pastoral de Turismo, Ávila.

Parga, E. \& Alonso González, P. (2019). Sustainable tourism and social value at world heritage sites: towards a conservation plan for Altamira. Annals of Tourism Research, 74, 68-80. https://doi.org/10.1016/j. annals.2018.10.011

Pinto, M., Ribeiro, R., Nunes, M. J., Araújo, E., Santos, L. A., Cunha, L., Gonçalves, A., Martins, M. L. \& Durand, J-Y (2016). Bugiada e Mouriscada de Sobrado: a festa como património. In M. Menezes, J. D. Rodrigues \& D. Costa (Eds.), Congresso Ibero-Americano património, suas matérias e imateriais. Lisboa: LNEC/ISCTE-IUL.

Pinto-Coelho, Z. \& Pinto, R. (2018). Discursos e imagens do turismo cultural. Revista Lusófona de Estudos Culturais, 5(2), 7-21.

Quinn, B. (2009). Festivals, events and tourism. In T. Jamal \& M. Robinson (Eds.), The SAGE handbook of Tourism Studies. http://dx.doi.org/10.4135/9780857021076.n27

Rickly-Boyd, J. M. (2012). Authenticity \& aura: a Benjaminian approach to tourism. Annals of Tourism Research, 39(1), 269-289. https://doi.org/10.1080/14616688.2012.762691

Ritzer, G. \& Liska, A. (1997). McDisneyization" and "post-tourism": complementary perspectives on contemporary tourism. In C. Rojek \& J. Urry (Eds.), Touring cultures: transformation of travel and theory (pp. 96-109). London: Routledge.

Santos, I. N. \& Azevedo, J. (2019). Compressão do espaço-tempo e hiperlocalização: os novos flâneurs. Comunicação e Sociedade, 35, 239-257. https://doi.org/10.17231/comsoc.35(2019).3141

Santos, M. da G. M. P. (2006). Espiritualidade, turismo e território - estudo geográfico de Fátima. São João do Estoril: Edição Principia.

Secall, R. (2009). Turismo y religión. Aproximación histórica y evaluación del impacto económico del turismo religioso. Retirado de https://www.diocesisoa.org/documentos/ficheros/Esteve_Rafael_-_texto_786.pdf

Semana Santa deve promover justiça social e humanismo (2015, 29 de março). Diário do Minho.

Silva, M. \& Ribeiro, R. (2018). O turismo religioso em Braga: a perspetiva dos residentes sobre a Semana Santa. In E. Araújo, R. Ribeiro, P. Andrade \& R. Costa (Eds.), Viver em/a mobilidade: rumo a novas culturas de tempo, espaço e distância. Livro de atas (pp. 162-172). Braga: CECS.

Tendeiro, I. (2010). A igreja de Santo António de Lisboa e o turismo religioso. Dissertação de Mestrado em Turismo, Escola Superior de Hotelaria e Turismo do Estoril, Portugal.

Turismo Porto e Norte de Portugal (2011). Estudo do perfil do turista na Semana Santa em Braga. Braga: Turismo Porto e Norte de Portugal.

Tutiaux-Guillon, N. (2013). Éduquer au développement durable ou enseigner le développement durable en histoire-géographie: enjeux sociopolitiques et discipline scolaire. Revue Phronesis, 2(2), 114-121.

UNWTO (2016). Network of religious tourism. Project brief. Retirado de http://cf.cdn.unwto.org/sites/all/files/ pdf/nrt_proposal_flyer-14july2016-lowres.pdf 
Wiśniewski, L. (2019). Religious tourism in Christian sanctuaries: the implications of mixed interests for the communication of the faith. Church, Communication and Culture, 3(3), 199-220. https://doi.org/10.1080/ 23753234.2018 .1537674

\section{NOTAS BIOGRÁFICAS}

Emília Rodrigues Araújo é professora no Departamento de Sociologia, da Universidade do Minho e investigadora do Centro de Estudos de Comunicação e Sociedade. Participa em vários projetos de investigação e tem diversas publicações que cruzam as temáticas da cultura, ciência e tempo.

ORCID: https://orcid.org/oooo-0003-3600-3310

Email: era@ics.uminho.pt

Morada: Centro de Estudos de Comunicação e Sociedade, Universidade do Minho, Campus de Gualtar 4710-057 Braga, Portugal

Márcia Silva é doutoranda em Sociologia, no Instituto de Ciências Sociais da Universidade do Minho e investigadora no Centro de Estudos de Comunicação e Sociedade. Com mestrado em Sociologia e licenciatura em Geografia e Planeamento, tem desenvolvido a sua investigação, sobretudo, temas da mobilidade e do turismo.

ORCID: https://orcid.org/oooo-0o03-3464-2194

Email: marciasilva.formacao@gmail.com

Morada: Centro de Estudos de Comunicação e Sociedade, Universidade do Minho, Campus de Gualtar 4710-057 Braga, Portugal

Rita Ribeiro é professora do Departamento de Sociologia, do Instituto de Ciências Sociais da Universidade do Minho. Doutorou-se em Sociologia, em 2008, pela Universidade do Minho, onde fez também mestrado em Antropologia. É investigadora do Centro de Estudos de Comunicação e Sociedade, no grupo de investigação em Estudos Culturais. Tem desenvolvido investigação na área da Sociologia da Cultura, em particular, sobre identidades culturais e manifestações de cultura popular. Coordena o projeto "FESTIVITY - Festa, património cultural e sustentabilidade comunitária. Investigação e comunicação no caso da Bugiada e Mouriscada de Sobrado".

ORCID: https://orcid.org/oooo-0002-2330-1696

Email: rmgr@ics.uminho.pt

Morada: Centro de Estudos de Comunicação e Sociedade, Universidade do Minho, Campus de Gualtar 4710-057 Braga, Portugal

\section{Submetido: 10.05.2019}

Aceite: 02.09.2019 